\title{
Antes de existir o Brasil: os portugueses na Índia entre estratégias da Coroa e táticas individuais
}

\author{
Andréa DORÉ
}

\begin{abstract}
Resumo: Este artigo propõe-se a discutir os fatores que contribuíram para a conformação das possessões portuguesas às margens do Oceano Índico, nomeadamente a construção de fortalezas ao longo da costa. Essa conformação representou uma estratégia oficial de fixação no território e de controle das rotas comerciais. Simultaneamente, no entanto, os indivíduos buscaram outras formas de enriquecimento, muitas vezes contrárias aos interesses da Coroa portuguesa. Para a análise desses dois movimentos, apoia-se na definição de estratégias e táticas proposta por Michel de Certeau.
\end{abstract}

Palavras-chave: Estado da Índia portuguesa; Fortalezas portuguesas; Estratégias e táticas.

O Brasil custou a ganhar o primeiro papel no teatro da expansão ultramarina de Portugal. Útil, promissora, mas não essencial, a posse do Novo Mundo não foi durante todo o século XVI, e nem nos inícios do século seguinte, a principal arma econômica ou simbólica a sustentar a potência portuguesa. Ainda em 1648, o padre Antonio Vieira escreveu um arrazoado a pedido de D. João IV em que aconselhava a entrega de Pernambuco aos holandeses visando a preservação do Estado da Índia portuguesa, pela "pouca consideração que tem Pernambuco com tudo isto", diante do que se tinha na Ásia: a conversão de "tantos reinos e impérios regados com o sangue de

- Professora Doutora - Departamento de História - Universidade Federal do Paraná - UFPR - 80060.000 - Curitiba - PR - Brasil. E-mail: andreadore@ufpr.br

HISTÓRIA, São Paulo, 28 (1): 2009 
tantos martyres, que é a maior dilatação da fé, que nunca teve a egreja" (NEVES, 2003: 167).

Este artigo pretende apontar elementos que contribuem para a compreensão da forma como os portugueses se instalaram na costa do Oceano Índico a partir da viagem de Vasco da Gama, em 1498, e puderam ali construir as bases de uma ampla rede de comércio - de produtos e de ideias - da qual o Brasil é fruto. Esse ensaio de interpretação não poderá abordar vários outros aspectos fundamentais para dimensionar e analisar o poderio português na Ásia, seus interesses, compromissos e rivalidades. Tendo, no entanto, como ponto de partida um mapa das possessões portuguesas, o objetivo é discutir os fatores que contribuíram para que este poderio assim se configurasse.

Em 22 de janeiro de 1586, o humanista florentino Filippo Sassetti escreveu de Cochim, na costa do Malabar, uma carta ao seu amigo Bernardo Davanzati em que comentava que os portugueses tinham ali o apelido de "battiplajas", que quer dizer "varre-praia", atribuído, segundo Sassetti, por um negro ao se referir ao fato dos portugueses não entrarem um palmo terra adentro (SASSETTI, 1995: 165) ${ }^{1}$. Esta é apenas uma das inúmeras referências à permanência dos portugueses no litoral da Índia, observada por viajantes italianos e recomendada pelas autoridades régias. O mapa dos enclaves portugueses às margens do Índico mostra com clareza essa conformação litorânea.

Alguns aspectos concretos ajudam a explicar essa ausência de inclinação dos portugueses em enfrentar a terra firme. O problema, então, está em identificar algumas razões que levaram Portugal a traduzir sua presença no Oceano Índico na construção de fortalezas pela costa; de que forma essa decisão se aplicou ao longo do século XVI; quais teriam sido seus mentores e que oposição enfrentou. Os estabelecimentos portugueses assim configurados estiveram na base de uma dominação cercada, ou seja, uma dominação restrita a um espaço rigorosamente delimitado, construído e mantido pela força militar, que sofre pressão externa,por parte de reinos locais 
locais ou concorrentes, e pressão interna, por meio de instituições que visam garantir a ordem, a hierarquia e os costumes. O espaço no interior das fortalezas representou todo um projeto, uma utopia, do qual se tentou afastar as impurezas, do plano social e religioso, e no qual se semearam anseios cristãos e ocidentais bastante rigorosos. Como sugere Mircea Eliade:

Nos limites deste mundo fechado começa o domínio do desconhecido, do não-formado. De um lado, existe um espaço cosmicizado, uma vez que habitado e organizado. Do outro lado, fora desse espaço familiar, existe a região desconhecida e temível dos demônios, das larvas, dos mortos, dos estranhos - ou seja, o caos, a morte, a noite (ELIADE, 1996, 34).

$\mathrm{Na}$ "região desconhecida", diríamos ainda: os infiéis, os gentios, os hereges. Esses processos modernos de civilização, que incluem a configuração de um espaço, guardam semelhanças com posturas de sociedades arcaicas e tradicionais ao conceberem o mundo que as cerca como um microcosmo.

Podemos identificar três aspectos concretos que teriam permitido a manutenção de praças portuguesas nos portos asiáticos. Em primeiro lugar, uma cultura das fortificações, florescente nos séculos XV e XVI na Europa, sobretudo na Itália, e que diz respeito à estratégia de defesa militar e controle de territórios. Por toda a Europa foram construídos fortes, castelos fortificados, fortalezas, cidades amuralhadas. Os complexos defensivos, mais ou menos sofisticados, foram abundantes nas regiões de fronteira e imprescindíveis nas cidades-estado italianas. $O$ pintor e iluminurista Francisco de Holanda, protegido de D. João III, e por este enviado a cidades italianas, escreveu que "não há nenhuma, desde a ínclita e nobilíssima cidade de Roma até a menor fortaleza de Civita Castelana, que não tenha um forte castelo ou fortaleza, a que eles chamam Roca, donde se recolham e defendam do inimigo no tempo da guerra" (HOLANDA, 1984: 17). A própria definição de cidade passava, assim, como o foi para os antigos, pela existência de muralhas. 
Os séculos XV e XVI viveram, na esteira das manifestações do Renascimento, a valorização e o incremento das técnicas de fortificação; a grande invenção nessa matéria sendo o baluarte, suporte da moderna artilharia de fogo. (MOREIRA, 1994: 85; NUNES, 1988: 54-62). Da Península, essa "mentalidade abaluartada" (PEREIRA, 1994:39), como chamou Mario Pereira, seguiu para as possessões do ultramar, onde se buscou reproduzir não apenas um espaço seguro, primeira função das muralhas, mas igualmente delimitado, ordenado e ainda - talvez como princípios a organizar toda uma utopia - católico e português.

As técnicas de fortificação tiveram ampla aplicação quando da saída portuguesa para o mar, considerando-se, conforme o faz a historiografia da expansão, os inícios do século XV como o período que marca um início sem retorno das descobertas marítimas. Neste sentido, a conquista de Ceuta, em 1415, inauguraria, sem o saber, uma sucessão de conquistas no norte da África e na costa ocidental africana efetivadas pela construção de fortes e fortalezas.

Segundo análise de Charles Boxer, na primeira etapa da expansão portuguesa, entre a tomada de Ceuta e o regresso de Vasco da Gama, em 1499, as muralhas estavam aliadas a um relacionamento momentaneamente pacífico com as populações da costa do Ouro da Baixa Guiné e tinham a função de demonstrar o poder e a força do reino de Portugal (BOXER, 1972: 39-53). Assim, foram construídos castelos e fortes, como o de São Jorge da Mina, na Guiné, em 1482 e o de Axim, em 1503. O objetivo era defender o comércio do ouro dos europeus em geral, e dos espanhóis, especialmente, e intimidar as populações de quem se adquiria o metal. As explorações pela costa africana são bastante conhecidas, mas, ao que nos interessa, elas representaram o aprendizado de um conjunto de práticas, não só de domínio de técnicas da navegação, mas também militares e, igualmente importantes, comerciais e diplomáticas.

A experiência tanto no Marrocos como na costa da Mina representa o segundo aspecto a construir a abordagem portuguesa no Índico. Nos dois espaços, os portugueses se 
mantiveram próximos ao litoral e não puderam, num longo primeiro momento, se envolver com as populações locais além do necessário para a realização do comércio. Da mesma forma, no norte da África, verificam-se duas formas de exploração que estiveram também presentes no momento em que a expansão ultrapassou o Cabo da Boa Esperança. Uma pode ser considerada mais independente e alheia a uma política "estatal" - a ação corsária -, mesmo que a Coroa não tenha estado ausente desse tipo de atividade. A outra, representava a estratégia da Coroa de dirigir e controlar os benefícios - o comércio pacífico na costa. As experiências acumuladas na África foram, assim, transplantadas e adaptadas para as margens do Índico. Tanto na Guiné do século XV, como na Índia do século seguinte, a fortaleza veio depois da feitoria.

A contribuir fortemente para a manutenção das praças portuguesas ao longo da costa, houve um terceiro elemento: a organização dos reinos asiáticos, a formar uma sequência de cidades mais ou menos autônomas, sultanatos independentes, como Quíloa, Ormuz, Malaca (BOUCHON, 1990: 73), voltadas para o mar e interligadas por dinâmicas rotas de comércio. Essa configuração tornava o modelo africano inicialmente eficaz, uma vez que atendia aos objetivos da exploração comercial. Na pena de homens de armas e de letras, a cultura das fortificações aliouse à compreensão da realidade encontrada na Ásia. Capazes de enfrentar duas forças, a dos asiáticos e a dos estrangeiros, assim como garantir a integridade de um espaço ocidentalizado, as fortalezas pareciam a estratégia mais adequada a ser adotada.

Geveniève Bouchon aponta dois fatores, que podemos considerar estruturais, capazes de explicar a potência econômica concentrada nas cidades portuárias da costa indiana: os acidentes naturais e o mau estado das estradas, que fazia com que muitos portos estivessem mais ligados entre si do que com o interior. A conformação notadamente costeira do comércio asiático fez a fortuna dos mercadores muçulmanos e, no que toca à Europa, atraiu aventureiros e homens de negócios, cujos relatos comprovam o dinamismo do roteiro marítimo. Há, no entanto, uma razão histórica para essa geografia econômica. 
Assim como a Ásia do Sudeste, a Índia viveu um processo de islamização que alterou o perfil de sua organização política, econômica e social, de forma mais profunda quanto maior foi a penetração do islamismo. Ao mesmo tempo em que o Islã surgia na Arábia, na primeira metade do século VII, a religião bramânica renascia sobre o budismo da Índia e, com ela, as proibições ligadas à navegação de longa distância. $O$ hinduísmo considerava as viagens marítimas como fonte de poluição porque expunham os embarcados às contaminações provocadas pela comida compartilhada com castas impuras. Os homens de castas mais elevadas não se aventuravam nessas viagens; e, da mesma forma, as evitavam os das outras castas. Bouchon explica que o comércio exterior da Índia se viu, então, nas mãos de comunidades estrangeiras ao hinduísmo, como os judeus estabelecidos no Malabar, ou os "cristãos de São Tomé" que exerceram o monopólio do comércio da pimenta (BOUCHON, 1997: 130$)^{2}$.

A proibição religiosa pode ter contribuído para que o poder político dos hindus se concentrasse em estados agrários que voltavam, muitas vezes, as costas para o litoral, resultando no quadro descrito por Lodovico de Varthema ao tratar de Calicute: "A gente natural desta terra não navega muito pelo mundo, mas os mouros são os que tratam com as mercadorias" (VARTHEMA, 1978: 831 e THOMAZ, 1994). A restrição religiosa é, porém, insuficiente para explicar o predomínio muçulmano no grande comércio marítimo. A existência de uma ampla rede ligada à religião surge como uma razão bastante forte. Os muçulmanos detinham o controle de importantes áreas de produção das especiarias, como Malaca e Achém, no norte de Sumatra, das zonas que serviam de intermediárias para a venda à Europa Aden, Alexandria, Cairo - e de pontos, os sultanatos, por todo o trajeto. Segundo Panikkar, o comércio do Ocidente com o Malabar levara ao crescimento de um império árabe que,

estendendo-se do Sind ao Marrocos, deu um ímpeto ao comércio do Malabar e ajudou os portos malabares a estabelecer estreitas conexões com o Cairo, Tunis, Baçora e outros portos 
ANTES DE EXISTIR O BRASIL: OS PORTUGUESES NA ÍNDIA...

maometanos, o que perdurou até os tempos da chegada de Vasco da Gama (PANIKKAR, 1997: 6s).

Tendo em vista um espaço mais alargado, no entanto, é difícil afirmar que os hindus não praticavam o comércio de longa distância. Senão, como explicar sua presença na Ásia do Sudeste, anteriormente à chegada do Islã? Como afirma Denys Lombard, na Ásia do Sudeste, onde a influência da Índia foi predominante durante séculos, vigorou fundamentalmente uma ordem agrária. No século IX iniciou-se a circulação dos mercadores árabes pela região e a paulatina disseminação do Islã. A conversão a uma das "religiões do Livro" trouxe vantagens para as populações atuantes no comércio de especiarias que, não mais ligadas a uma religião vinculada a um local determinado, como muitas religiões étnicas, associaram-se a grupos mais afortunados. Os sinais de adesão exteriores, como a proibição religiosa ligada à alimentação no caso do Islã, foram muitas vezes suficientes para garantir a integração na comunidade muçulmana, não importando muito o conhecimento da doutrina (SCHOUTEN, 1999: 247s). A mesma lógica pode ser localizada mais tarde, quando da chegada dos portugueses e dos interesses identificados pelas elites locais na conversão ao cristianismo (DORÉ, 2008: 227-243).

A partir do século XV, surgiu nesse "carrefour javanais", para usar a expressão de Denys Lombard, um novo tipo de estado, o sultanato, o que significou o simultâneo florescimento de cidades na costa (LOMBARD, 2004). Os grandes centros urbanos do sudeste asiático deixaram de se desenvolver nas planícies agrárias e passaram a se concentrar nos portos, voltados para o mar e o grande comércio. O desenho das cidades também se alterou. Ele não era mais geométrico, nem orientado em função dos pontos cardeais e o centro não era mais ocupado por um templo localizado na montanha ou pelo palácio real. Surgia:

uma outra concepção do espaço, concepção que não é mais concêntrica ou centrípeta. O centro do mundo não é mais o meio 
do palácio real, mas está muito distante, além dos mares, na Meca para onde os peregrinos convergem a partir de todos os pontos da terra habitada (LOMBARD, 1980: 438).

Como resultado desses imbricados movimentos nos espaços asiáticos, os portugueses tiveram de enfrentar as alterações que se propagaram e se adaptaram de uma região à outra do grande continente, o que levou Subrahmanyam a alertar para "as dinâmicas da história asiática" como um problema essencial no momento de estudar as ações portuguesas na Ásia (SUBRAHMANYAM, 1995: 13). Esse ponto de vista coloca-se em oposição à leitura tradicional que tende a ver a Ásia como um continente estático onde reinaria a "longa duração" e ao qual se aplicaram as teorias do "modo de produção asiático" ou do "despotismo oriental". O conceito de modo de produção asiático, forjado por Karl Marx a partir das especificidades da organização econômica da sociedade indiana, principalmente, nasceu da dificuldade em inseri-la nos modos de produção característicos da Europa ocidental. A idéia do despotismo oriental, por sua vez, é muito mais antiga e se mistura com outras imagens arquetípicas construídas sobre o continente asiático. Uma dessas imagens associava a Ásia, e principalmente a Índia, à sabedoria, encarnada nos "filósofos nus", nos brâmanes. Ao lado da relação de filiação que o Ocidente buscou estabelecer com os brâmanes, esteve uma outra, marcada pelo desejo de exclusão. Tratava-se de denunciar o abismo que os separava de seus ancestrais - os filhos de Noé ou os sábios da Antiguidade, Pitágoras e Platão, sobretudo - e os condenava a serem homens degenerados. Os brâmanes encarnavam, desta forma, para os homens de fé - e as missões jesuítas na Ásia muito contribuíram para essa visão - a tirania de uma falsa religião, marcada por práticas atrozes e grosseiras (WEINBERGER-THOMAS, 1988: 1519). Nos séculos seguintes, essas interpretações colocariam esta parte do mundo, assim como seus habitantes, num estágio inicial - e superado - da evolução humana. Segundo Fernando Catroga, foi na segunda metade do século XVIII, a partir do Essai sur les moeurs (1756) de Voltaire, que se passou a compreender a 
História como um processo universalizador, protagonizado pela Europa, onde ao Oriente cabia ser um passado a enaltecermos irremediavelmente decadente e estático, estando certos povos, como a China e a Índia, condenados "a serem meros degraus necessários à emergência dos portadores do futuro" (CATROGA, 1999: 199).

Podemos, então, perguntar: a construção de fortalezas ao longo da costa no Oceano Índico fazia parte de uma estratégia mais ampla de conquista e de dominação deliberadamente engendrada pela Coroa portuguesa? Diante das experiências e dos interesses portugueses, podemos sugerir que a construção de fortalezas foi a primeira e mais importante atitude antecipadamente prevista, e que, frente à complexidade das situações encontradas na Ásia, Portugal não se viu obrigado a desenhar uma política específica para o Índico, mas percebeu que sua abordagem tradicional responderia também às condições encontradas naquelas regiões, ou seja, "novos espaços, antigas estratégias" (ANDRADE, 1999: 35-44). A conformação dos reinos asiáticos, que foi se descortinando ao longo dos primeiros anos, parecia demandar um conjunto de medidas que privilegiasse o litoral. Para compor este modelo de controle marítimo com o apoio em terra, instituiu-se um sistema de armadas que fiscalizavam a distribuição de cartazes aos reinos aliados.

Os cartazes eram um salvo-conduto concedido a reinos aliados para que pudessem dispor de um número de navios e de viagens pré-determinado pela Coroa portuguesa. O interesse dos portugueses se fixava, sobretudo, em coibir a ação dos mercadores no mar Arábico, a fim de impedir que a pimenta seguisse o caminho do Estreito de Meca e chegasse aos portos do Mediterrâneo. Essa circulação fortaleceria tanto os mercadores levantinos como os muçulmanos da Índia, daí o fato de a maioria dos cartazes ter sido emitida para viagens ao Estreito, ou seja, era naquela região que se concentrava o controle português, assim como a ação punitiva das armadas. Somente nos anos 1570 passou a ser mais freqente a emissão de cartazes para a Ásia do Sudeste. Essa medida foi uma resposta à 
retomada do comércio da pimenta pelo Mar Vermelho, fruto das alianças entre os turcos otomanos, que então controlavam o Estreito, e o sultão de Achém, ao norte da ilha de Sumatra, poderoso inimigo dos portugueses e grande produtor de especiarias.

Para compreender em que espaço os portugueses passaram a atuar, é preciso ter em mente que não se tratava, então, de um cenário estático, que coube aos recém chegados desestabilizar. As ações portuguesas tornam-se mais compreensíveis quando lidas como respostas às oportunidades encontradas e não necessariamente como frutos de um protagonismo eurocêntrico. Os envolvimentos em conflitos locais pré-existentes estiveram na origem de muitas alianças que resultaram em estabelecimentos duradouros; as relações diplomáticas, mais exitosas quanto maior fosse o conhecimento das especificidades locais, foram tão importantes quanto a guerra.

Objetivamente, as fortalezas representavam neste contexto o braço ao mesmo tempo protetor da presença portuguesa e controlador das ações dos próprios portugueses. No reino, era praticamente unânime a opinião de que elas representavam a única forma de assegurar o monopólio sobre as redes de comércio até então manipuladas pelos árabes no Índico. O que nem todos aceitavam, no entanto, como acontecera também na costa ocidental da África, era que o monopólio régio consistia na maneira mais vantajosa de interferir nessas mesmas redes. $O$ projeto messiânico de D. Manuel, preocupado com o fortalecimento e a dilatação do reino português, enfrentava uma linha mais independente, interessada no comércio pacífico mais do que na conquista. Esta última integrava em suas fileiras opositores ferrenhos da política régia, como o grupo de Cochim, que se opôs ao governador Afonso de Albuquerque nos anos 1510 e chegou a escrever ao rei em dezembro de 1512 que "tudo é vento, senão Cochim; aqui fazei vosso pé firme pera sempre, porque toda las fortalezas, feitas e por fazer, vos não servem de nada $[. . .]^{\prime 3}$. 
Este é o lado do, mesmo que vulnerável, planejamento oficial dos primeiros anos dos portugueses na Índia. Fortalezas, armadas, conversão de lideranças locais, cartazes, tratados de paz, direitos alfandegários, comércio pacifico com aliados e guerra aos inimigos. Houve, no entanto, um outro lado, composto por um conjunto bastante heterogêneo de atitudes e que, seguramente, compôs os espaços do império português; foram atitudes levadas a cabo por indivíduos sem respaldo político ou institucional.

A atenção que os anônimos da expansão portuguesa têm recebido tornou mais complexa a questão que opunha os interesses do Estado aos de particulares. Também não se trata mais, como afirma Jorge Manuel Flores utilizando-se das categorias descritas por Vitorino Magalhães Godinho, do "fidalgo-comerciante" a dividir o espaço com o "negociante enobrecido" (FLORES, 1993: 27). A mobilidade dos homens superou esses enquadramentos e fez surgir um outro que divide os portugueses na Ásia em servidores do rei e rebeldes, estando neste segundo grupo vários casos que culminam no renegado, entendido não apenas como o apóstata da religião cristã, mas, sobretudo, como o traidor (CRUZ, 1998: 179). Os "lançados, alevantados e desorelhados" (FLORES, 1993: 27) citados pelos textos da época, os "portoghese vagabondi", que o viajante italiano Cesare Fedrici encontrou no reino de Pegu nos anos 1580, mudavam de lado na tentativa de se adaptar à realidade asiática.

Trata-se aqui dos que, voluntaria ou involuntariamente, deixaram o reino para tentar melhor sorte na Índia e viveram fora das muralhas. Se muitos eram forçados a partir para a Índia ou o faziam sem refletir sobre os riscos envolvidos, o retorno ao reino, por sua vez, também não era simples. A Coroa proibia que deixassem as Índias sem licença dos vice-reis e governadores "por ser de muito grande inconveniente a meu serviço e ao bem e conservação do estado da India"4. Mesmo por terra tentou-se controlar a volta a Portugal, só sendo permitida a licença a pessoas de muita confiança. Neste caso, esperava-se tanto manter os homens na Índia como evitar que, ao retornarem ao 
reino, espalhassem pela rota dos infiéis - pelos portos do Mar Vermelho - e dos rivais - os entrepostos venezianos no Mediterrâneo - informações sobre os estabelecimentos portugueses no Índico.

Os degredados, no âmbito da política oficial, formavam um grupo à parte. Punidos por delitos no reino ou em outros espaços coloniais, os degredados passavam a servir nas feitorias e fortalezas portuguesas e tinham o maior interesse em fugir do cerco imposto, neste caso, por seus próprios aliados. “Cabialhes, para além de explorar os sertões, contactar inimigos e aliados dúbios, recolher informações entre populações desconfiadas ou encabeçar os ataques mais sangrentos" (LOPES, 2000: 448). Sua contínua fuga da jurisdição portuguesa para auxiliar reinos adversários chegou a indicar que o envio de criminosos à Índia acabava sendo prejudicial, "por não servir naquellas partes mais que de fugir para as terras dos mouros e gentios, donde vem contra os mesmos Portugueses" (Doc. de 26.03.1669, apud SOUZA, 1998: 602).

Fugiam assim do controle português, degredados do reino, criminosos do próprio ultramar ou os que desejavam melhores oportunidades e se aliavam a um outro grupo, de homens livres que negociavam também a fé: os renegados, ou arrenegados. Para estes, a política do governador Afonso de Albuquerque, no início da presença portuguesa na Índia, foi um grande motor. Sua postura controladora e centralizadora estaria na origem da dispersão de muitos portugueses para o sudeste asiático e da criação de colônias espontâneas longe do alcance da administração portuguesa em Goa (SOUZA, 1998: 602s) $)^{5}$. Igualmente, a política que a sucedeu, de Lopo Soares de Albergaria (1515-1518), marcada por "grande soltura", foi responsável pelo despovoamento das praças portuguesas, com a dispersão das guarnições interessadas em se dedicar à mercancia. O vice-rei deu largueza aos homens para que fossem buscar sua vida por onde quisessem, resposta que os portugueses souberam dar, como bem observaram viajantes italianos como Cesare Fedrici e Filipo Sassetti. 
O resultado semelhante de duas políticas opostas, uma de controle excessivo, outra de estímulo a iniciativas particulares, e que teria se acentuado na segunda metade do século XVI, nos leva a seguir a conclusão de Maria Augusta Lima Cruz. Segundo a historiadora, muitos dos renegados eram exilados convictos apenas à espera de uma ocasião para se evadirem, além do que a estrutura de classe da sociedade portuguesa na Ásia fazia "da deserção, o ser 'vira-casacas', e a marginalização elementos integrantes dos processos desenvolvidos no século XVI" (Apud SUBRAHMANYAM, 1994: 158).

Muitos desses renegados eram estrangeiros. $O$ viajante italiano Lodovico de Varthema encontrou em Calicute, ao retornar das ilhas Molucas, dois cristãos milaneses: Giovanmaria e Pietroantonio. Haviam chegado à Índia com Vasco da Gama, em sua segunda viagem, em 1502, fingindo ser joalheiros. Durante o ataque do Samorim de Calicute a Cochin, no ano seguinte, fugiram com o invasor, para quem passaram a trabalhar, conhecedores que eram da técnica de fusão de artilharia. Os dois afirmaram a Varthema estar entre os primeiros homens do rei de Calicute, e que todos os dias falavam com ele. Queriam voltar à Europa, mas não sabiam por qual via. Por aquela que tinham vindo não era possível, "porque eram fugitivos dos portugueses" (VARTHEMA, 1978: 870). Tinham, com razão, medo dos portugueses, pois além de fazer artilharia, haviam ensinado a técnica aos gentios. Apesar do empenho que Varthema afirma ter empregado junto ao então vice-rei D. Lourenço de Almeida para perdoar os dois milaneses, estes foram denunciados como espiões por um escravo e mortos por mercadores mouros de Calicute.

Sem, no entanto, serem perseguidos pela justiça, muitos homens preferiram buscar melhor sorte fora das áreas controladas pela administração do Estado da Índia, e com freqüência, cedo ou tarde, retornavam aos espaços portugueses. Nesse caso há uma diferença entre os que se refugiavam nos sultanatos de Bijapur e Ahmadnagar, não muito distantes de Goa, e os que seguiam para o Golfo de Bengala e o sudeste asiático. No primeiro quadro, os homens que voltavam ao 
controle da Coroa, entre eles muitos fidalgos, esperavam ao menos manter o nível social em que se encontravam quando partiram. Na segunda situação, “a fronteira geográfica podia funcionar como fronteira social ${ }^{\prime \prime}$.

Eles agiam como embaixadores autônomos e obtinham autorização para a construção de fortalezas onde o braço estatal ainda não alcançara, intervindo, como fariam as autoridades portuguesas em muitas ocasiões, nos conflitos locais. Assim fez Diogo Veloso, nos últimos anos do século XVI, acompanhado pelo castelhano Blas Ruiz de Hernán González, que liderou uma campanha militar contra o rei do Camboja. Ao obter sucesso em suas "aventuras", esses homens tinham a possibilidade de subir na hierarquia oficial, obedecendo aos padrões da sociedade lusoasiática, como ocorreu com Filipe de Brito, a quem o rei concedeu o Hábito de Cristo e o título de fidalgo da Casa Real, após obter autorização para edificar uma fortaleza em Siriam (SUBRAHMANYAM, 1994: 161-165).

O papel de intermediários desempenhado por esses homens permite afirmar que sua ação deixou muitas vezes de ser periférica e significou, por vias pouco convencionais, a expansão das áreas de atuação do Estado. A estrutura militar que servia de base para as ações estatais tinha o duplo efeito de garantir alianças quando o interesse local era por proteção, mas também $o$ de afastar possíveis aliados contrários às interferências portuguesas no comércio.

Essa função de intermediários foi também exercida por fortalezas, cujas relações com as populações circundantes, hostis ou condescendentes, eram inevitáveis. Para descrevê-las nos parece bastante pertinente considerá-las como "sociedades intermediárias", comportando elementos asiáticos e europeus. Um "intermediário" pode ser definido "como uma pessoa que coloca em contato dois mundos que são praticamente fechados um ao outro, fazendo uso das possibilidades de que dispõe"7. No caso dos portugueses na Ásia, há uma galeria de exemplos, a começar por João Machado, dos tempos de Afonso de Albuquerque, (CRUZ, 1993: 39-46) ou Miguel Ferreira, que atuou entre a Pérsia e o Coromandel durante toda a primeira metade 
do século XVI (FLORES, 1993: 21-32). Do lado dos asiáticos, podemos citar inicialmente dois indivíduos que desempenharam essa função: Timoja, o mercador hindu que participou da tomada de Goa por Afonso de Albuquerque (SANTOS, 1999: 99-101), e o quelin Nina Chatu, que ajudou os portugueses a tomarem Malaca e atuou depois como parceiro no comércio (THOMAZ, 1994: 486-512).

As observações de viajantes italianos na Índia indicam que a presença portuguesa era visível na paisagem urbana da Ásia desde o início do século XVI. A rede de fortalezas - base territorial do império asiático português - refletia-se numa sucessão de cidades visitadas que, com exceção da tríade Calicute-Cochin-Goa, não foi alterada pelos portugueses (DORÉ, 2002). Ao mesmo tempo, essa presença teve como característica uma profunda contradição: a administração do Estado da Índia se impunha um cerco voluntário enquanto os súditos portugueses buscavam liberdade e lucros sem respeitar fronteiras. A preocupação da Coroa era livrar o espaço que lhe pertencia da presença de estrangeiros, de hindus, mouros ou judeus, assim como de cristãos indesejáveis. Aos homens perigosos, no entanto, aos cristãos que algum mal pudessem trazer ao domínio português - renegados, principalmente - se abriam exceções perdoando seus crimes. Aos soldados era preciso obrigar a freqüentar o espaço da fortaleza.

A primeira imagem de uma ocupação litorânea programada, atendendo a objetivos comerciais satisfeitos pelo dinamismo das rotas de mercadores, desdobra-se, assim, nas ações múltiplas dos indivíduos. Como conciliar esses dois lados, sem cair na armadilha - durante muito tempo seguida - de que os impérios coloniais foram construídos com base em planos prédefinidos e que os temas a serem estudados nesta trajetória são aqueles que ajudam a entender o quadro final? Uma história teleológica em que os processos confirmam as conclusões que já conhecemos. Por meio desta concepção de história, os renegados, os prisioneiros, os traidores, as mulheres e os escravos desempenham papéis definidos de forma homogênea para cada grupo, possuem a "unidade da noite", como afirmou 
Michelet ao estudar as feiticeiras (MICHELET, 1992:7), ou representam aparições fruto do acaso e sem consequências.

Os dados empíricos demonstram que o isolamento das fortalezas não correspondia a todos os elementos presentes no contexto estudado. Conclui-se, então, que as formas de fixação no território adotadas pela Coroa e seus homens, que redundaram em modelos de dominação e exploração do comércio, devem ser entendidas como estratégias, no sentido dado por Michel de Certeau. Estratégia é

o cálculo (ou a manipulação) das relações de forças que se torna possível a partir do momento em que um sujeito de querer e poder [...] pode ser isolado [a Coroa portuguesa]. A estratégia postula um lugar suscetível de ser circunscrito como algo próprio [uma burocracia, um corpo legislativo] e ser a base de onde se podem gerir as relações com uma exterioridade de alvos ou ameaças.

Paralela à compreensão das estratégias está a compreensão das táticas:

a ação calculada que é determinada pela ausência de um próprio. Então nenhuma delimitação de fora lhe fornece a condição de autonomia. A tática não tem lugar senão o do outro. E por isso deve jogar com o terreno que lhe é imposto tal como o organiza a lei de uma força estranha. [...] Em suma, a tática é a arte do fraco" (CERTEAU, 2007: 99-100).

O que se verifica, no caso dos portugueses na Índia, é a variedade e a variabilidade dos usos que se fez da estrutura de dominação e das leis, normas e edificações que a sustentaram e deram forma.

Os domínios portugueses na Ásia no período aqui estudado representaram uma ambiciosa utopia: a transplantação de uma ordem cristã no seio de sociedades muito diversas capaz de garantir, por meio da solidariedade religiosa, uma rede de comércio seguro e lucrativo. O império que esta utopia pôde construir, porém, nasceu e se manteve sitiado, produzindo, no 
entanto, nas brechas da monumentalidade de suas fortificações, um sem número de experiências individuais que recusam qualquer enquadramento. Considerar, assim, que estratégias e táticas conformam um processo dinâmico e imprevisível permite analisar o resultado, neste caso, a formação de espaços portugueses em vários continentes no início da era moderna, como um conjunto mais rico e complexo de atitudes, interesses, indivíduos em que as ações aparentemente isoladas e inconsequentes contribuem para o entendimento do todo.

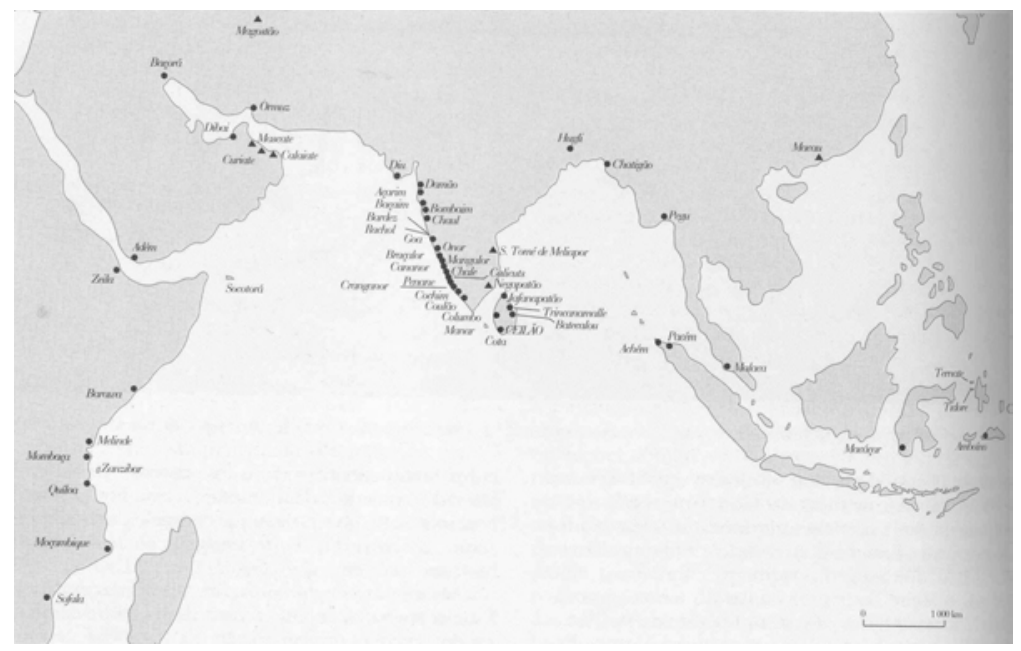

Mapa das localidades controladas ou frequentadas pelos portugueses na Ásia.

Fonte: Francisco Bethencourt \& Kirti Chaudhuri (dir.). História da expansão portuguesa. Vol. I. Lisboa: Círculo de Leitores, 1998, p. 397.

\section{REFERÊNCIAS BIBLIOGRÁFICAS}

ANDRADE, Amélia Aguiar. "Novos espaços, antigas estratégias: o enquadramento dos espaços orientais". In: Os Espaços de um Império. Estudos. Lisboa: CNCDP, 1999.

BOUCHON, Geneviève, Vasco de Gama. Paris: Fayard, 1997. 
. "L'Ocean Indien à l'époque de Vasco da Gama". In: Mare Liberum, $\mathrm{n}^{\circ} 1,1990$.

BOXER, Charles. O Império colonial português (1415-1825). Lisboa: Edições 70, 1972.

CATROGA, Fernando. "A história começou a Oriente". In: $O$ orientalismo em Portugal. Séculos XVI-XX. Lisboa: CNCDP / Inapa, 1999.

CERTEAU, Michel de. A invenção do cotidiano. 1. Artes de fazer. Petrópolis: Vozes, 2007.

CRUZ, Maria Augusta Lima. As andanças de um degredado em terras perdidas: João Machado. Mare Liberum, nº 5, 1993.

. Degredados e arrenegados portugueses no espaço índico. Revista Textos de História. Vol. 6, n 1-2, 1998.

DORÉ, Andréa. Cristãos na Índia no século XVI: a presença portuguesa e os viajantes italianos. Revista Brasileira de História. Vol. 22, $\mathrm{n}^{\circ} 44$, dez. 2002.

. "As atuações no Reino do Congo e na Costa da Pescaria: aproximações para o estudo do Império Português no século XVI". In: DORÉ, Andréa, LIMA, Luís Filipe Silvério e SILVA, Luiz Geraldo. Facetas do Império na História: conceitos e métodos. São Paulo: Hucitec, 2008.

ELIADE, Mircea. Imagens e símbolos. São Paulo: Martins Fontes, 1996. FLORES, Jorge Manuel. Um 'homem que tem muito crédito naquelas partes': Miguel Ferreira, os "alevantados" do Coromandel e o Estado da Índia. Mare Liberum, $\mathrm{n}^{\circ}$ 5, 1993.

HOLANDA, Francisco de. Da Fábrica que Falece à cidade de Lisboa. Introdução, notas e comentários de José da Felicidade Alves. Lisboa: Livros Horizonte, 1984.

LOMBARD, Denys. "Le concept d'empire en Asie du Sud-Est". In: DUVERGER. Maurice (dir.). Le concept d'empire. Paris: PUF, 1980.

. Le Carrefour javanais. Essais d'histoire globale. Paris: Editions de l'EHESS, 2004 (1ª. Ed. 1990).

LOPES, Ricardo. "Degredados e arrenegados na armada de Pedro Álvares Cabral". In: OLIVEIRA E COSTA, João Paulo Oliveira (org.). Descobridores do Brasil. Exploradores do Atlântico e Construtores do Estado da Índia. Lisboa: Sociedade Histórica da Independência de Portugal, 2000.

MICHELET, Jules. A feiticeira. Rio de Janeiro: Nova Fronteira, 1992.

MOREIRA, Rafael. "Caravelas e baluartes". Arquitetura Militar na Expansão Portuguesa. Lisboa: CNCDP, 1994. 
NEVES, Luiz Felipe Baeta. Terrena cidade celeste. Imaginação social jesuítica e inquisição. Rio de Janeiro: Atlântica editora, 2003.

NUNES, António Lopes Pires. O castelo estratégico português e a estratégia do castelo em Portugal. Lisboa: Direcção do Serviço Histórico Militar, 1988.

PANIKKAR, K.M. Malabar and the Portuguese. New Delhi: Voice of India, 1997 ( $1^{\circ}$ ed. 1929).

PEREIRA, Carlos Renato Gonçalves (org.). História da Administração da Justiça no Estado da Índia. Século XVI. Lisboa: Agência Geral do Ultramar, 1964-1965. 2 vols.

PEREIRA, Mário. "Da torre ao baluarte". In: Arquitetura Militar na Expansão Portuguesa. Lisboa: CNCDP, 1994.

SANTOS, Catarina Madeira. "Goa é a chave de toda a Índia". Perfil político da capital do Estado da Índia (1505-1570). Lisboa: CNCDP, 1999.

SASSETTI, Filippo. Lettere dall'India (1583-1588). A cura di Adele Dei. Roma: Salerno Editrice, 1995.

SCHOUTEN, Maria Johanna. "Quelques communautés intermédiaires en Insulinde Orientale". In: LOUREIRO, Rui M. \& GRUZINSKI, Serge (coord.). Passar as fronteiras. Lagos, 1999.

SOUZA, Teotónio de. "Carreira, escalas e o serviço penal ao serviço do Império". In: A Carreira da Índia e as rotas dos estreitos - Actas do VIII Seminário Internacional de História Indo-Portuguesa. Angra do Heroísmo, 1998.

SUBRAHMANYAM, Sanjay. O efeito Kagemusha. As armas de fogo portuguesas e o Estado no sul da Índia no início da época moderna. História: Questões e Debates. Curitiba, n. 45, pp. 129-154,2006.

. "A cauda abana o cão: o subimperialismo e o Estado da Índia". In: Comércio e conflito. Comércio e conflito. A presença portuguesa no Golfo de Bengala 1500-1700. Lisboa: Edições 70, 1994.

. Império Asiático Português. 1500-1700. Uma história política e econômica. Trad. Paulo Jorge Sousa Pinto. Lisboa: Difel, 1995.

THOMAZ, Luís Filipe F. R. "Calecute". In: Dicionário de História dos Descobrimentos Portugueses, vol. I. Direcção de Luís de Aluquerque. Lisboa: Círculo de Leitores, 1994.

. Diogo Pereira, o Malabar. Mare Liberum. no 5, 1993.

. De Ceuta a Timor. Lisboa: Difel, 1994.

VARTHEMA, Lodovico de. "Itinerario di Lodovico Barthema in Arabia, in India e nell'Asia Sudorientale". In: RAMUSIO, G. B.. Navigazioni e Viaggi. Torino: Giulio Einaudi editore, 1978, Vol. I. 
WEINBERGER-THOMAS, Catherine. "Introduction. Les yeux fertiles de la mémoire. Exotisme indien et représentations occidentales". In: L'Inde et l'imaginaire. Paris: Editions de l'EHESS, 1988.

ZINADÍM. História dos portugueses no Malabar. Lisboa: Cotovia, 1998, pp. 118s.

DORÉ, Andréa. Before Brazil existed: the Portuguese in India from the Crown's strategies to individual tactics. História, v.28, n.1, p.169-190, 2009.

\begin{abstract}
This article proposes a discussion of the factors that contributed to the settling within the Portuguese possessions along the shores of the Indian Ocean, namely the construction of fortresses along this coastline. These settlements represented an official strategy of establishment within the territory and of control of the commercial routes. Simultaneously, however, private individuals sought other forms of becoming wealthy which were very often contrary to the Portuguese crown's interests. The analysis of these two lines of action is based on the definition of strategies and tactics proposed by Michel de Certeau.
\end{abstract}

Keywords: The State of Portuguese India; Portuguese fortresses; Strategies and tactics.

\title{
NOTAS
}

${ }^{1}$ Carta a Bernardo Davanzati. Cochim, 22.01.1586. O autor escreve "scopaliti", que traduzo aqui por "varre-praia".

${ }^{2}$ Segundo Panikkar, não se sabe ao certo quando os judeus e cristãos chegaram ao Malabar, mas há evidências de comunidades prósperas no século VII. Ver PANIKKAR, 1997: 4s. Sobre a presença de judeus e cristãos antes da chegada dos muçulmanos ver também ZINADIM, 1998: 118s.

${ }^{3}$ Carta de António Real a El-Rei. Cochim, 15.12.1512. Apud THOMAZ, 1993: 55. Diogo Pereira foi um dos principais integrantes da união 
contra o governador Afonso Albuquerque, responsável pelas conquistadas de Ormuz, Goa e Malaca. Luís Filipe Thomaz contrapõe o termo "imperialista" ao "liberal" para nomear as principais correntes à época existentes em Portugal. O primeiro não recebe a conotação que o termo ganhou no século XIX, mas incorpora a idéia de formação de um "império universal", cristão, ainda nos moldes medievais, como o queria, por exemplo, Dante Alighieri segundo a sua Da Monarquia. Falar de "liberais" pode parecer um pouco excessivo, mas aqui se refere ao grupo que se mostrava contrário ao monopólio do Estado, mas não descartava a proteção que pudesse por este ser oferecida. Ver também SUBRAHMANYAM, 1995: 136-141.

${ }^{4}$ Provisão régia de 12.03.1592 (PEREIRA, 1964-64: II-289). Ver também Alvará régio de 14.02.1613 na mesma obra.

${ }^{5} \mathrm{O}$ termo renegado, diferente de rebelde ou mercenário, designava os portugueses que se convertiam ao Islão e que optavam por se colocar aos serviço de um rei muçulmano. Incluem-se, então, como explica também Maria Augusta Lima Cruz, tanto apóstatas quanto traidores. Ver SUBRAHMANYAM, 1995: 352-361 que retoma também a trajetória de alguns arrenegados na Ásia.

${ }^{6}$ SUBRAHMANYAM, 1994: 167. Grifo do autor. Num outro artigo, Subrahmanyam trata do papel de particulares portugueses como disseminadores das armas de fogo pelos estados asiáticos. SUBRAHMANYAM, 2006: 97-123.

${ }^{7} \mathrm{O}$ conceito de intermediário, no sentido cultural, foi muito utilizado pela Antropologia a partir dos anos 50 em seguida ao estudo de Eric Wolf sobre o México ("Aspects of group relations in a complex society: Mexico". In: American Anthropologist. no 88, 1956, pp. 1065-1079.) Ver SCHOUTEN, 1999: 245s.

Artigo recebido em 03/2009. Aprovado em 05/2009 